\title{
في التصوف المقارن: ملاحظات منهجية
}

\section{عرفان عبد الحميد}

التصوف: ظاهرة دينية تتسم بالعالمية، فلا تتقيد بحدود الزمان والمكان، والأجناس واللغات والأديان،

$$
\text { أو الدوائر الحضارية، "فلا وطن لها ولا تاريخ ميلاد."1 }
$$

ومع هذه السمة العالمية للظاهرة فإن من الصعب، إن لم يكن من المستحيل، وضع تعريف جامع مانع

للتصوف يتضمن كل مفرداته، كتجربة جوانية وجدانية وخبرة دينية، هذا ما استقرت عليه آراء الباحثين في الظاهرة على اختلاف أديافم وتباين مناهجهم، ممن تناولوها بالدراسة والتحليل، سواء من الصوفية أنفسهم أو ممن درسها من مؤرخة التصوف المقارن ومن ثم: "فليس لتعريف مهما دق أن يكون ذا معنى، شاملاً وواضحاً، ويتضمن جملة الخبرات التي توصف عادة بالوعي الصوفي. إنه شبه المفاهيم النفسية الأخرى التي لا تسمح بطبيعتها بالتعريف وتستعصي عليه."2

وسبب هذه الصعوبة التي تقترب من حدود الاستحالة كما قلنا جملة أسباب يمكن أجمالها فيما يأتي:

أولاً: إن التجربة الصوفية مهما تباينت صورها، وتعددت أنماطها - كما سنشير - تجربة فردانية خالصة

تنزع إلى الاحتجاز دون المشاركة ولا تستهوي إلا القلة من أتباع الأديان عموماً، وتنطوي بطبيعتها على نزوع باطني ف فهي في جوهرها حالة نفسية وموقف وجداني، لا هي تخضع -ولا يهتم من يعانيها ويكابدهابالنسقية المنطقية كما هو الحال في المذاهب الفلسفية والكلامية والفقهية، أو حلِّها بالتعبير عنها في مفاهيم

* مكتوراه في الفلسفة الإسلامية من جامعة كمبردج 1965، أستاذ الفلسفة والفكر الإسلامي بالجمعة الإسلامية العالمية في ماليزيا.

1 James, William. The Varieties of Religious Experience, New York: Doubleday \& Company, Inc, 1978, p.370

2 Eliada, Mircea (editor). Encyclopedia of Religion, MacMillan Publishing Co., 1987, Vol.2 p.305-311

3 Dan, Joseph. Jewish Mysticism and Jewish Ethics, London: Jason Aronson Inc., 1996, p.IX 
دقيقة ومنضبطة. ذلك أن اهتمام الصوفي ينصرف عادة إلى ترجمة فحوى ومضمون التجربة التي يكابدها ومن ثم فإن العبارات مهما دقت لا تنقل المضمون الحقيقي للتجربة. 4

ويزيد هذه الصعوبة بياناً الفيلسوف الديني المعاصر بول تلش قائلاً: إن الحركة الصوفية تعكس عدم الرضى بأية واحدة من طرائق التعبير الجامدة عن المطلق والمقدس، فالذي يكابد التجربة الصوفية -عادةيتخطى ويتجاوز مثل تلك التعبيرات وتمظهراتما المتعددة. إن المقدس المطلق يقع خارج العالم ويُجاوز صور تمظهراته الخارجية المشخصة المتعينة والمباشرة.

ومرد هذه الصعوبة هو أن الصوفي -وفي مختلف الدوائر الدينية والثقافية- إنما يصدر عن قناعة راسخة مفادها أن الحقيقة الكلية تجاوز الخبرة الإنسانية العادية والاعتيادية المستفادة من الحواس أو الخطاب بالكتابة والقول أو الاستدلال ثم هو يعتقد بأن، الوسائل البشرية المعتادة في الخطاب غير قادرة على التعبير عن الحقيقة الإلمية، إذ الحقيقة الصوفية مما لا يمكن الإشارة إليها بالعبارات، وحتى الإيماءات الرمزية الغامضة التي يتوسل بها البيان الصوفي إلى مقصوده؛ لا تضيف جديداً إلى المقصود. إنها خبرة خخصوصة لا يككن فهمها إلا ممن يتذوقها بذاته، أو من صوفي قرين له كابد التجربة بنفسه، والذي له نوع تذوق للمتجاوز، الخفي المستور

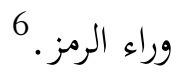

ثانياً: وإزاء هذه الصعوبة التي تقترب من حدود الاستحالة، ومحاولة من الصوفي نقل مضامين بحربته إلى الأغيار والآخرين توجد صعوبة مضافة، فلأن وسائل الاتصال من اللغة العادية والخطاب والفكر، لا تستوعبها يضطر إلى التعبير عنها بلغة مخصوصة تتسم بالثِعرية والتمثيل والرمزية والمجاز وتنطوي عادة على رلى التناقض: والرمز كما لا يخفى، يستر من المعاني قدر ما يظهر، فهو ظهور وخفاء معاً وفي آن واحد. 7

$4 \quad$ Eliada, Mircea (editor). Encyclopedia of Religion, ... p.305-311

5 Tillich, Paul. The Encounter of Christianity with World Religions, Fortress Press: Minneapolis, 1994, p.71

6 Dan, Joseph. Jewish Mysticism and Jewish Ethics, ... p. IX 7 ibid. 
بل المستفاد من دراسة التجربة الصوفية أها عندما تبلغ ذروة عنفواها، تتبدى في صيغة متناقضة وعبارات مبهمة غامضة، مما اصطلحوا عليها بالشطحه وقد لا تستوعب حتى هذه الشطحات المراد، فلا يبقى أمام الصوفي إلا الركون إلى "الصمت" بحيث إذا أراد النطق بما وجد لم يقدر وهذا هو "الخرس" كما سماه الشيخ محيي الدين بن عربي (1240-1165)9 في سبق تاريخي فريد للمعاصرين من الفلاسفة وعلماء النفس المعنيين بدراسة الظاهرة الصوفية، أمثال وليم جيمس (1910-1842م) في كتابه The , , ولوفيج فتجنشتاين (1901-1889 (1981) في كتابه: Experience of Religious المقالات tractatus فقد جعل الأول - كما سيمر بنا- الاستعصاء على التعبير العلامة الأولى المميزة للتجربة الصوفية، وأكد الثاني بأن ما هو "ثمرة للتجربة الصوفية لا يمكن التعبير عنها" وسمى قبلهما رويزيك (ت/1381م) هذه الحالة "بالسكوت المعتم."10

وقد أشار شيوخ الصوفية في الإسلام إلى هذه الصعوبة في التعبير عن فحوى الخبرة الصوفية وترددت

باستمرار في مدوناهم الإشارة إلى تلك الصعوبة وأسباها، فيقول أبو بكر محمد الكلابابذي (ت 390هـ/10000م): "مشاهدات القلوب ومكاشفات الأسرار لا يمكن العبارة عنها على التحقيق، بل تعلم بالمنازلات والمواجيد، ولا يعرفها إلا من كابد تلك الأحوال وحل تلك المقامات."11 ويقول الإمام أبو القاسم عبد الكريم بن هوزان القشيري (ت 465هـ/1076م): "وهذه الطائفة يستعملون ألفاظاً بينهم قصدوا بها الكشف عن معانيهم لأنفسهم والإجمالَ والسترَ على من باينهم في طريقتهم، لتكون معاني ألفاظهم مُستَبْهمة على الأجانب، غيرة منهم على أسرارهم من أن تشيع في غير أهلها."12 ويؤكد حجة الإسلام الغزالي هذه التقريرات في مدوناته الصوفية عامة فيقول: "أعلم أن بعضاً من مسائلك التي سألتني عنها لا يستقيم جوابها

عرفت الصوفية في الإسلام الرمز تعريفات مختلفة ولكنها متشال]ة، فعرفه الطوسي في "اللمع" بالقول: الرمز معنى باطن مخزون تحت كلام

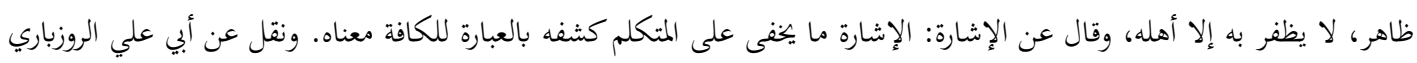

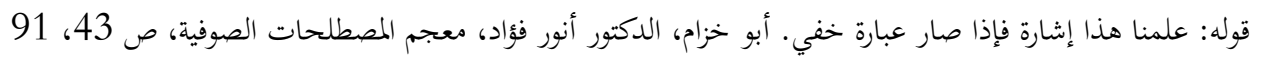

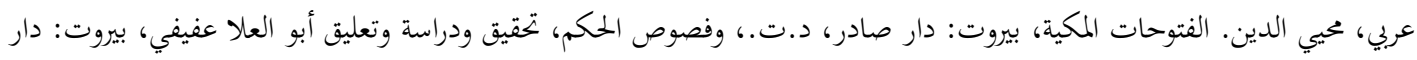

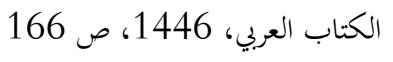
10

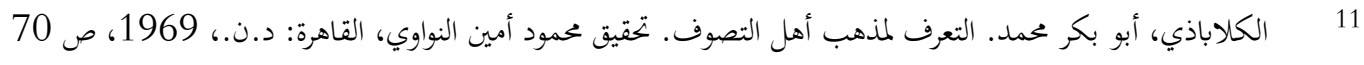

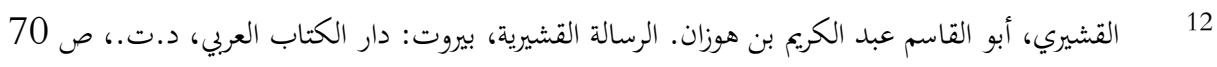


بالكتابة والقول، إن تبلغ تلك الحالة تعرف ما هي، وإلا فعلمها من المستحيلات، لأهما ذوقية وكل ما يكون ذوقياً لا يستقيم وصفه بالقول كحلاوة الحلو ومرارة المر لا تعرف إلا بالذوق، فمن ذاق عرف!"13 وقد حاول شيخ الصوفية أبو عمر السهروردي البكري (ت 632هـ/1234م) بيان وجه الصعوبة في صياغة تعريف جامع وشامل للتجربة يستغرق كامل مفرداتا ومضامينها، فقال في مدونته المعتمدة لدى عامة الصوفية: "في حين أمكن تعريف علوم الفقهاء وحدها بالعبارة، لأهما علوم ورسوم تنال بالتعلم والاكتساب، فإن علم التصوف ليس مما يمكن حده لأنه إشارات وبواد وعطايا وهبات يغرفه أهلها من بحر العطاء الذي لا ينتهي مدده."14

وقد تناول العلامة محمد إقبال الظاهرة الصوفية من وجهة نظر نقدية تحليلية فذة، وانتهى إلى تقرير وجهة نظر الصوفية في هذا الخصوص، وقال ملخصاً وجه الصعوبة في وضع تعريف عام وجامع لمصطلح التصوف والخبرة الصوفية، فقال: "وبما أن المعرفة الصوفية معرفة مباشرة، فمن الراجح أنه لا يمكن الاطلاع عليها، أي نقلها لإنسان آخر، ذلك أن الحالات الصوفية أشبه بالشعور منها بالتعقل، إن محتويات الشعور الديني لا يمكن الاطلاع عليها، أي نقلها للآخرين"، وقوله هذا شبيه بما قرره العلامة نيكلسون في كتابيه "صوفية الإسلام" (ص 29) و"التصوف الإسلامي وتاريخه" (1947، ص 97) حيث يقول: "إن صوفية الإسلام -وشأغم في ذلك شأن الصوفية جميعاً- يدركون أن الغاية التي يتوجهون إلى تحصيلها من الطريق الصوفي ليست مما يقع في نطاق العلم أو الوصف بالألفاظ، فليس لغير من يتذوق أحوال الصوفية أن يفهم

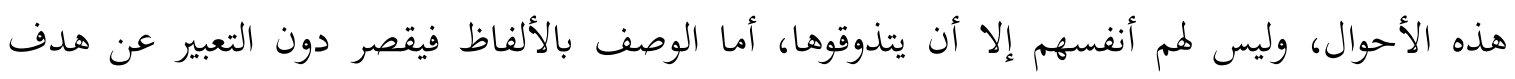

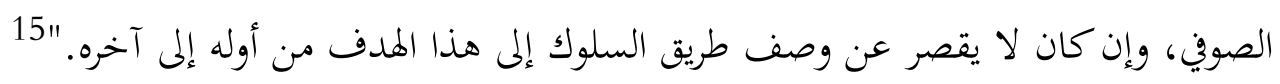
وقد لخص فأوفن بالمراد الفيلسوف الديني المعروف شلاير ماخر (1834-1768) هذه الوجوه التي ذكرناها في صعوبة وضع تعريف جامع ومانع للخبرة الصوفية، وأخا خبرة مخصوصة مباشرة وليست بحاجة إلى

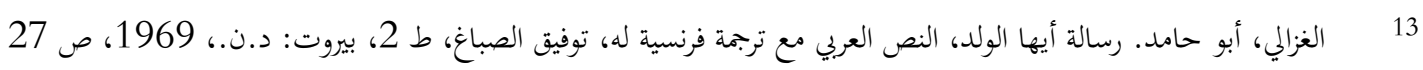

$$
\begin{aligned}
& 14
\end{aligned}
$$

15 Eliada, Mircea (editor). "Philosophy of Religion", Encyclopedia of Religion, ... p.309-310 
شهادة منتحلة لصدقها من خارجها، فقال: "إن الخبرة الصوفية، خبرة معيشة، إذا بتحاوز إمكانات القول والكتابة والادراك الفكري، إفها مما لا يمكن فهمه إلا من خلال المعاناة الذاتية، ومع ذلك فهي لحظة تتسم بالعالمية في الخببرة الإنسانية العامة، متجذرة باستقلال في لحظة إشراق ذاتي، هي وليدة ذاتا، ليست بحاجة إلى شهادة تصديق أو تبرير منتحل، من خارجها."

ثالثاً: ثم إن التجربة الصوفية، ليست بتجربة متشكِكة وهوية ثابتة وقارة، بل هي بطبيعتها تجربة نامية ومتطورة تبعاً لسلم المعراج الروحي الذي يكابده الصوفي، ومع هذا التطور الصاعد في مقامات روحية متتابعة والتي تصحبها حالات نفسية هي الأخرى متطورة تتكثف التجربة وتتعمق فتتباين صورها، وقد أشار العلامة ابن خلدون إلى هذه الصعوبة المضافة قائلاً: "وقد حاول كثير من القوم العبارة عن معنى التصوف بلفظ جامع، يعطي شرح معناه، فلم يف بذلك قول من أقوالهم، فمنهم من عبر بأحوال البداية، ومنهم من عبر بأحوال النهاية، ومنهم من عبر بعلامة، ومنهم من عبر بأصوله ومعانيه، ومنهم من جعل ذلك الأصل والمبنى واحداً، وأمثال هذه العبارات كثير وكل واحد يعبر عما وجد بحسب مقامه، والحق فإن التصوف لا ينطبق عليه حد واحد"، 16 وقال مؤكداً هذا في "المقدمة" (ص 373، الفصل الخاص بالتصوف): "ليس البرهان والدليل ينفع في هذا الطريق، رداً أو قبولاً، إذ هي من قبيل الوجدانيات." وقد سبق الإمام الغزالي غيره في الإشارة إلى الطبيعة النامية والمتطورة للتجربة الصوفية وأثرها في استحالة وضع حد جامع مانع لها فيقول: وهؤلاء أقوالهم تعرب عن أحواهم، فلذلك تختلف أجوبتهم ولا تتفق، لأفم لا يتكلمون إلاعن عالتهم الراهنة الغالبة عليهم"، 17 ويشير في مناسبة أخرى قائلاً: "وكلام الصوفية أبداً يكون قاصراً، فإن عادة كل واحد منهم أن يخبر عن حال نفسه"، 18 وإلى هذا المعنى ذهب العلامة نيكلسون حيث يقول: "إن التعاريف المتعددة للصوفية التي وردت في الكتب العربية والفارسية، وإن كانت ذات فائدة تاريخية (لأفا تكشف عن التطور التاريخي للمصطلح)، فإن أهيتها الرئيسية هي في أها تعرض التجربة الصوفية على أها غير ممكن

$$
\begin{aligned}
& 16 \text { 17 } 17 \\
& 17 \\
& 18
\end{aligned}
$$


تحديدها، لأغم -أي الصوفية- يحاولون دائماً التعبير عما أحسته نفوسهم، ولن يكون تعريف مفهوم يضم كل خفية من الشعور الديني المستكن لكل فرد. (1937، ص 97

رابعاً: هذا كله إن نحن وقفنا عند حدود دراسة التجربة الصوفية في دائرة دينية بعينها وأديان مرتكزها النبوة والوحي الإلهي (اليهودية والمسيحية الإسلام) أو أديان غير مؤسسة على نبوة ووحي كالهندوسية بفروعها والبوذية بمذاهبها وهي أديان تتفاوت بين التوحيد والتعددية الوثنية ومرتكزها الجوهري القول بوححة الوجود، مادية كانت أم روحية. أما إذا نظرنا وحللنا الظاهرة الصوفية بوصفها ظاهرة تعم الأديان جميعاً المنزلة والوضعية، فثمة صعوبة أخرى مضافة تتبدى للباحث في خصائصها تتمثل في الأنماط المتعددة والصور المتباينة لما نصطلح عليه عموماً بالتجربة الصوفية التي تتمظهر عادة وتتجسد في أنماط متنوعة وصيغ متباينة ما سنأتي على ذكرها، فالتجربة والخبرة الصوفية عامة "تتخذ صوراً وتعبر عن نفسها في طرائق متعددة." "19 ذلك أن المتصوف يحاول عادة وفي الغالب من الأحيان صياغة تجربته على ورفق الدائرة الحضارية والثقافية ومحددات الإطار العقدي العام للدين الذي ينتمي إليه ويؤمن بأصوله الإيمانية، فيجهد من أجل ربط بتربته الروحية بمما، أعني تفسير محتويات الخبرة وفقاً لتعاليمها، طلباً للشرعية الدينية والثقافية لمشورعه الذاتي وتحربته الفردية التي هي من قبيل الوجدانيات كما أسلفنا، وعن هذا المفهوم فإن مؤرخ الحركة الصوفية لا بد له أن ينتبه إلى مرحلتين متتابعتين للحركة الصوفية في الأديان، بخاصة الأديان السماوية، مرحلة طوفان الحركة الصوفية على هوامش الدين الخارجية، كظاهرة هامشية مدانة، مستنكرة ومرفوضة، ومرحلة محوالة الحركة التوافق مع الأصول الكبرى للدين الذي نبتت في إطارهكي تتحول الظاهرة عبر عمليات إعادة بناء حسامة من مشروع متهم بالإدانة والاستنكار إلى الإقرار بشرعيتها، والاعتراف بها يقول هانز كونج في هذا الصدد:

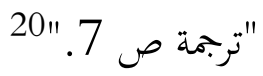

وهذه المحاولة للتوفاق مع الأصول العقائدية للدين المنزل تتخذ عادة صورة "الجمع بين الحقيقة والشريعة" كما جاء على لسان صوفية الإسلام، وصوفية الأديان السماوية الأخرى من اليهودية. وهذا

19 Eliada, Mircea (editor). "Mysticism”, Encyclopedia of Religion, ... Vol.10,

20 Kung, Hans. Judaism between Yesterday and Tomorrow, John Bowden (trans.), Cross Road Publishing Co.: New York, 1992, p 171 
التناقض بين الطورين للحركة الصوفية، طور الإدانة والاتحام، أولاً، ثم الاعتراف الشرعي بها، هو ما يفسر ظاهرة العداوة المستحكمة، التي اتسمت بالضراوة والشدة تارة، والسماحة والقبول تارة أخرى، بين الصوفية في الأديان السماوية عامة وبين الفقهاء والمتكلمين، فطالت الصوفية - في صورة أو أخرى- إدانة الفقهاء والمتكلمين لهم وصدور فتاوى دينية بالحرم ضدهم حصل هذا في اليهودية ضد صوفيتها المعروفة بحركة Elija Gaon of Vilna) (1720-( الحاسيديم-التقاة حيث حكم الراباي أليجا بن سلمون بن زلمان 1797) المتنفذ المتربع على عرش اليهودية التلمودية المتوارثة إبان القرن الثامن عشر- على طائفة التقاة الحاسيديم من الأشكناز بالهرطقة والزندقة وادعاء المخاريق وضربمم بالحرم وحكم عليهم بالطرد. وهكذا أيضاً كان الأمر في المسيحية الأولى، حيث اتمت حركة الرهبنة بالزيغ والابتداع، واستمر الأمر إلى أن تحولت الرهبنة إلى مؤسسة بابوية تخضع لسلطاها وتذغن لأوامر العقيدة الرسمية للكنيسة، ومع ذلك فقد تواصلت أحكام الإدانة الكنيسة ذد شخصيات وجماعات صوفية اتممت بالمروق عن العقيدة الرسمية للكنيسة، أمثال القديس أوريجون (ت 251م) ويوهانس مايستر ايكهار 1327-1J.M. Echart (1260) الذي اتمته السلطات الكنسية بالإلحاد والقول بوحدة الوجود، وظهرت جماعات من الغلاة في القرن الرابع عشر تولدت عن تعاليم صوفي هرطقي من أباعه هو 1381-1293 (Jan van Broeck اقمت بدورها بالنزعات العدمية واستحلال الحرمات وبحاوز المبادئ الأخلاقية، عرفوا بأسماء مختلفة مثل: أصدقاء الله وإخوان الحياة المشاة bretheren of common life وإخوان الروح الحرة bretheren of the free spirit بنزعاقم العدمية الفاضحة وإسقاط الفضائل الخلقية المتوارثة من الاعتبار.21 وأما قصة غلاة المتصوفة وزنادقة الزهاد في الفكر الصوفي الإسلامي فطويلة حاولنا أن نرصد مفرداتا في كتابنا نشأة الفلسفة الصوفية وتطورها.22 وبملة تلك النزعات الباطنية الهدامة يصطلح عليها في دائرة التصوفات العالمية بالاستخفاف

21 Smith, Margaret. An Introduction to Mysticism, London: Sheldon Press, 1979 22 فتاح، عرفان عبد الحميد. نشأة الفلسفة الصوفية وتطورها، بيروت: دار الجيل، 1993، ص 73-115 
بالأحكام الشرعية demonization of the sacrament أو اسقاط التكاليف الشرعية anti

23 .monialis

وبملة هذه الانحرافات في العقيدة وقواعد السلوك قد لخصها الإمام محمد بن علي الشوكاني في كتابه

الموسوم "الصوارم الحداد القاطعة لأرباب الاتحاد" (ص 61-75) مما سنشير إلى طرف منها في الصفحات

التالية، وأجملها في العصر الحديث الشيخ محمد رشيد رضا في قول جامع مختصر ودقيق، فقال: "والذي أستبطه من طول البحث والمقارنة، أن أكثر الذين خالفوا نصوص الشريعة بأقواهم وكتبهم من لابسي التصوف هم باطنية في الحقيقة ثم قلدهم كثير من المسلمين وهم لا يعرفون أصلها"(تاريخ الإمام، ج1، ص صد 115)، وقد سبق المتأخرين إلى هذا الترابط في الأفكار بين المتصوفة الغلاة وفرق الباطنية العلامة ابن خلدون فقال: "ثم إن هؤلاء المتأخرين من المتصوفة المتكلمين في الكشف... كان سلفهم مخالطين للإسماعيلية المتأخرين من الرافضة....فأشرب كل واحد من الفريقين مذهب الآخر واختلط كلامهم وتشابهت عقائدهم.

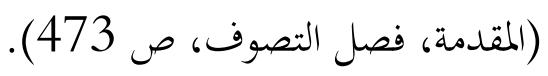

ونخن نؤكد أن الدرس المستفاد من الدراسات المقارنة للتصوفات العالمية هو أن التجربة الصوفية، وهي

تجربة فردانية عاطفية خالصة، كانت وفي كل الأديان والثقافات ساحة مشاعة ومفتوحة للفوضى الأخلاقية ما لم تلتزم بأدبي العقل والدين معاً؛ هذا ما قرره وأكده الإمام الغزالي أعظم شخصية صوفية حددت للوعي الصوفي إطاره الشرعي الموزون بالدين والعقل الذي هي كما أفاد "ميزان الله في الأرض" والذي طبع بمؤلفاته في الزهد والتصوف الفكر الديني في الإسلام، فهي هذه المؤلفات التي طبع بها عصره، كتبها الغزالي لأتباعه

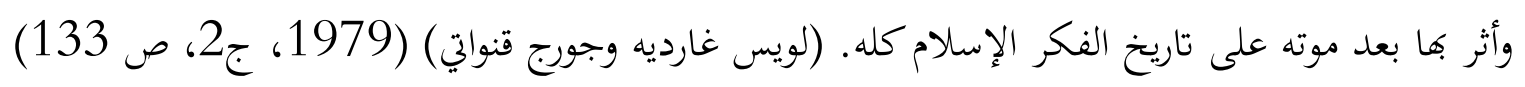
وقارن الغزالي، ميزان العمل، (القاهرة، 1342هـ، 1923).

وجوه اشتقاق مصطلح التصوف:

23 Tillich, Paul. The Encounter of Christianity with World Religions, Fortress Press: Minneapolis, 1994, p. 71 
ارجع الباحثون في تاريخ التصوف المقارن جذر المصطلح في اللغات الأوربية mysticism إلى أنه مشتق من الكلمة اليونانية muein التي تفيد الصمت وكم الأفواه والكلمة في أصلها اليوناني كانت وصفاً للمراسيم السرية الخاصة والإخراط في صفوف الأديان الظلامية السرية والتي كانت تفرض على المنضَمّ إليها الالتزام بالسرية التامة والامتناع عن إفشاء أسرار الجماعة، ضناً بها على الأغيار ومخافة من عداوة خصومهم

وقد سرت هذه النزعة السرية وكتمان التعاليم إلى الجماعات الغنوصية عامة في الفكر الديني، فني اليهودية عرف عن الأسينين عامة والغيورين منهم خاصة المعروفين بالمغارية المعروفين (الفرق والمقالات الإسلامية-الشهرستاني) لسكناهم في الكهوف والمغارات، قسم العهد الذي يؤديه من شاء الانضمام إلى جماعتهم، كذلك سرت مراسيم الكتمان والسرية وحفظ العهد والامتناع عن إفشاء السر إلى الجماعات الباطنية في الإسلام، كالإسماعيلية والقرامطة والنصيرية، والطوائف الصوفية التي جمعت بين الغلو الشيعي والغلو الصوفي معاً، مثل القلندرية والبكتاشية الذين جمعوا تعاليمهم السرية في دساتير عمل صارت تعرف عندهم بآيين نامة.

وتحت تأثيرات الفلسفة الأفلاطونية المحدثة وشيخها أفلوطين (ت 270م) مؤلف التساعيات المشهورة The Enneads النظري. وقد استبعد الباحثون هذا الوجه من الاشتقاق، أي رد المصطلح إلى التأمل النظري البجرد، لأنه يطلق أيضاً ويراد به المعرفة البحثية التأملية المستفادة من الاستدلال العقلي المنطقي.24

ومع هذه التحفظات والواردة، فإنا نعلم على وجه اليقين بأن المصطلح ظل وعلى الدوام وفي مختلف التصوفات يتضمن معنى الصمت والخرس وكَكَّه اللسان مقروناً بالامتناع عن إفشاء الأسرار ووجوب الكتمان عليها، خاصة عند الجماعات التي لفقت مذاهب صوفية ذات نزعات باطنية في اليهودية والمسيحية والإسلام. وهكذا كان الأمر أيضاً في البوذية والهندوسية، إذ دل المصطلح على الصمت المطلق في البوذية وفي الهندوسية وفي التاوية الصينية حتى ذهب وولتر رالف أنجي Walter Ralf Ange المؤرخ المتخصص 
في الآداب الصوفية إلى أن الصمت علامة مشتركة وعامة للتجربة الصوفية وذلك في كتابه عن التصوف المسيحي christian mysticism الذي يعد مرجعاً موثوقاً في دراسة التصوف المقارن.

وذهبت طائفة ثانية من مؤرخي التصوف المقارن إلى ربط المصطلح بما عرف في التراث المسيحي مصطلح mustikos الذي دل على المعاني الخفية المستورة وراء ظواهر النصوص الكتابية، بزعم أن لكل النصوص معاني ظاهرة واضحة ومباشرة وأخرى خفية مستورة وأن على الصوفي ألا يقنع بالمعاني الظاهرة بل يجاوزها إلى التماس المعاني المستورة للنص، فهي المراد على الحقيقة والمعبرة عن النص الكتابي. وسوف نلاحظ أن هذا الزعم هو حال صوفية الإسلام أيضاً.

ومعروف أن هذا المنهج الذي يجاوز الدلالة الظاهرية للنصوص الكتابية (التوراة) يرتبط تاريخياً باسم

فايلو الإسكندراني فيلون Philo الفيلسوف اليهودي المعاصر للسيد المسيح عليه السلام (15 ق م 40م) (انظر (155). Wilfon H.A.(1982), pp 7عنه أخذه أكابر آباء الكنيسة اللاتين أمثال كليمنت الاسكندراني (ت 215م)، وتلميذه الروحي من بعده القديس أوريجون (ت 251م) الذي يعد المعقق والمبدع الأول في المسيحية للتفسيرات الإشارية التي اتخذت عنده صورة ثلاثية، المعنى الحسي الظاهر، وهو من الكتاب جسده، وربما ندر وجوده، والمعنى النفسي أو الأخلاقي، وهو من الكتاب نفسه، تم المعنى النفحاني أو الروحاني، وهو من الكتاب روحه. 25 ثم اتخذ هذا التأويل صورة رباعية يتدرج من المعنى الحريف إلى المعنى الأخلاقي إلى المعنى الرمزي وأخيراً الدلالة الصوفية. وهذا التأويل الرباعي تبناه متصوفة اليهود المنتمين إلى حركة البالاة والمؤلف من التفسير الحريف ثم الرمزي فالمجازي فالتعبير الذوقي الباطني للنص.26 وفي اجتهادي المتواضع -الذي أرجو أن يكون صواباً- أن السبب الذي ساق إلى نشأة دعوة ثنائية: الظاهر والإشاري في الأديان السماوية وما دار حولها من خصومات طويلة وعنيفة بين الفقهاء والمتكلمين من جهة والصوفية من جهة أخرى راجع إلى أن الوحي الإلمي في نظر المؤمنين بمرجعيته المطلقة النهائية يمكن فهمه من زاويتين متضافرتين ومتضايفتين هما: باعتبار مصدره الغيبي الإلهي المفارق، فهو هذذه المثابة يسمو

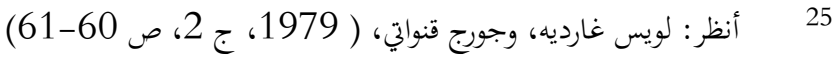

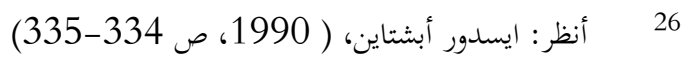


ضرورة على دلالات اللغة البشرية المعتادة، فلن يكون بوسعها استيعابه، وثانيهما: أن الوحي الإلهي رسالة وشرع وأحكام مخاطب بها المكلفون، من جميع المثدينين بهذا الوحي على تفاوت أفهامهم، ومن هذا الاعتبار لا بد أن يأتي الوحي أيضاً في عبارات بِيّنة وواضحة ومباشرة تتسع لما لغة البشر المعتادة عندهم، ولذذا وصف الحق تعالى كتابه المنزل تارة بالحكمة البالغة، وأخرى بأنه وحي بلسان عربي مبين، وأنه تعالى مراعاة لحال المرسل إليهم ما بعث رسولاً إلا بلسان قومه، فلا بد والحالة هذه أن يكون المعنى الإشاري امتداداً طبيعياً للمعنى اللغوي، لا راداً له أو بجاوزاً لدلالته المعتبرة في أصل اللغة فيكون آنئذ بمثابة: "دقائق تتكشف على أرباب السلوك"، كما أشار العلامة الألوسي في تفسيره (روح المعاني -7/1)، وإلا أصبح المعنى الإشاري تحريفاً للكلم عن مواضعه، وخارجاً عن حدود الكلمة عند أهل اللغة وعاداقم في استعمالاقمم، فلا يكون امتداداً للمعنى اللغوي، بل رداً له وتجوزاً لدلالثه. وهذا شأن الباطنية الملاحدة ودعواهم إن لكل ظاهر باطناً ينسخه ويتجاوزه، وكان غرضهم الأقصى من هذه الدعوة الملحدة - كما أكد الإمام الغزالي: "إبطال الشرائع، فإفم إذا انتزعوا عن العقائد موجب الظاهر، قدروا على الحكم بدعوى الباطن ما يوجب الانسلاخ عن الدين، وإذا سقطت الثقة بموجب الألفاظ الصريحة فلا يبقى للشرع عصام يرجع إليه ويعود عليه."27 ومع كل هذه الدلائل التي تربط المصطلح بالتفسيرات الإشارية، فإن عدداً من الباحثين ردَّ هذا الترابط لأن التجربة الصوفية في جوهرها -ومهما تباينت أنماطها وأشكالها- هي في اجتهادهم محاولة للاتصال بالحقيقة الكلية المطلقة الواحدة.28

ولا أرى لاعتراضهم مبرراً ووجاهة، إذ الثابت أن صوفية الأديان جميعاً قد جهدوا من أجل تحاوز المعنى الظاهري والحريف لنصوص الوحي الإلهي إلى المعاني الخفية والرمزية التي تعتبر الظواهر آنئذ بجرد إشارات للمعاني المستورة، مع الالتزام -عند الصوفية الملتزمين بأدب الدين والشرع- بالمعنى الظاهري ووجوب الوقوف عند دلالاته التكليفية، والغالب عند المتصوفة في الأديان التمثيل لما يقصدون بيجل الثلج المغمور في مياه المخيطات، عشره فقط ظاهر للعيان ودال على تسعة الأعشار المغمورة منه في الماء والتي لا ترى بالعين. 29

$$
27
$$

28 Dan, Joseph. Jewish Mysticism and Jewish Ethics, ..., 1996, pp. ix

29 ibid 
أما ما يتعلق بوجوه إشتقاق مصطلح التصوف في الإسلام، فقد تعددت التفسيرات لحدود بالغة، كما هو معروف للدارسين 30 مع انعقاد اجماع الرأي على أن الاسم: مستحدث لم يكن معروفاً -كما أشار القشيري في رسالته -قبل المائين للهجرة- فلا عبرة إذاً بمحاولات قدماء الصوفية ومن سلك سبيلهم من المحدثين ربط المصطلح بالصوف الخنشن وبالرسول الكريم عليه السلام، ومسلك صحابته الكرام، فتلك في نظري محاولات تبريرية مصطنعة ومنتحلة، قصدوا بها التماس الشرعية الدينية وشهادة التصديق التاريخية للحركة الصوفية بعد نشأهتا لأسباب كثيرة، لا بجال للخوض فيها. وتلك الوجوه من الاشتقاق قد أتت على تعدادها وذكرقا المدونات الصوفية التقليدية، كما هو معروف. وللمؤرخ الديني أن يأخذ في اعتباره -في هذا الخصوص- قاعدة محكمة مستقراة من الدرس التاريخي مفادها: أن جميع الاتحاهات في الفكر الديني العام تحاول استجداء الشرعية التاريخية والدينية على اجتهاداتا بالتوسل بأمرين متضايفين هما: التماس القدمية التاريخية لتوجهاتما ثم ربطها بالسلف الأول من أتباع الدين وذلك أن إحدى القواعد العامة المتحكمة في بنى الفكر الديني أن الحق لا بد أن يكون قديماً، وإذا كان كذلك لا بد وأنه قد نقل إلى الخلف من السلف بالتواتر.

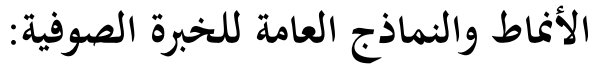

أحصى مؤرخة التصوفات العالمية وعلماء النفس والاجتماع المحدثين الأنماط التالية التي تعد وتعتبر بتربة

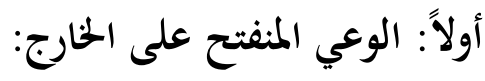

وفيه تتأحد الذات الإنسانية مع العالم الطبيعي الخارجي، ويصطلح علي تعريفه بالنمط المنفتح على الخارج أو التصوف المكتسب وأحياناً سمي بالتصوف الطبيعي أو الوعي الجواني المتأخذ بالطبيعة وجمالها. ويغلب على هذا النمط ألا يكون ذا مضمون ديني، وفيه تتأمل الذات الإنسانية الطبيعة ومظاهرها الجمالية المشخصة والمتعينة في الخنارج، وتتصورها على ما فيها من تنوع وتضاد: وحدة مؤتلفة نابضة بروحانية كامنة

30 
وخفية تسرى فيها، وروحانية تجاوز التنوع في الأفراد المشخصة إلى معنى الوحدة والجمال المطلق الخنفي وراءol

وعنده تسقط التناقضات والتمايز والتنوع بين المظاهر وأفراد الطبيعة، بحيث تبدو جميعاً وكأغا ثمرة

لشجرة واحدة، وبتليات لروح واحدة، وهذا النمط من الوعي الصوفي بالتأحد مع الطبيعة الخارجية نلثقيه William عند أتباع المذاهب الرومانسية من الشعراء والأدباء والفنانين (لخصه وليم وردوورث (Wordworth 1770-1850 في ديوانه التمهيد Prelude وعبر عنه الصوفي الكاثوليكي الدومينيكاني يوهانس مايستر إيكهارت 1327-1260 في مقولته التي سببت إدانته والحكم عليه بالحرمان والطرد من قبل السلطات الكنسية: "كل شفرة عشب وقطعة خشب وحجر هي بحليات لوحدة كونية واحدة." وأورد مقولته المبشرة بوحدة وجود طبيعية من بعده في القرن السادس عشر المتصوف البروتستانتي يعقوب بيمه Jacob Boehme (ت 1624) الذي صرح بلغة وحدة وجود مادية خالصة أن الله كائن في الطبيعة. 31 وهكذا الحال مع النفس الإنسانية عند هذه الطائفة القائلين بهذا النمط من الوعي الصوفي، ففيها نزوع فطري موروث للتأحد مع الكل الكوني وأن هذا التأحد هو مصدر الحيوية في الإنسان وباعثها. ثانياً: النمط المنكفيء على الذات:

وهذا النمط من الوعي الصوفي، وهو الأكثر تطوراً من سابقه، بل أنه المراد والمقصود عموماً من مصطلح التجربة الصوفية، وفيه يفقد الصوفي وعيه، عبر عملية تطهرية شاقة فيها مكابدة ومعاناة معيشة هي معراج روحي في درجات متصاعدة، عُرفت عند آباء الكنيسة وعند صوفية الحاسيديم اليهود وعند صوفية الإسلام للفناء. وينتهي هذا المعراج إلى غياب الوعي بالذات والأغيار بل وزوال وفناء الوعي بكل معطيات الحس والفكر أو الاستجابة لدواعي الرغبات والشهوات، بالتأحد بالكلية في الحق الواحد المطلق في لغة الفلاسفة من الصوفية أو بالخالق تعالى في لغة متصوفة الأديان السماوية، فتختفي كل تفرقة بين الذات

31 Great Books of the Western World. "The Introduction", Chicago: Encyclopedia Inc., 1990, Vol. 1, Ch. 29 (God), pp. 433-470 
وموضوع إدراكها، وهو المقام الذي أسماه الإمام الغزالي وصوفية الإسلام بالاستغراق بالكلية في الله تعالى وأسماه الإمام ابن تيمية بالفناء الشهودي تمييزاً له عن الفناء الوجودي وعرف في التصوفات الهندوسية والبوذية بالاتحاد بالنفس الكلية عبر معراج روحي تطهري ذي مقامات ثمانية هي (الطريق النبيل ذو الثماني شعب): سلامة الرأي، سلامة النية، سلامة القول، سلامة الفعل، سلامة النفس، سلامة السعي، سلامة الوعي، وسلامية التركيز. ثم التحقق بالطمأنينة الجوانية المطلقة المقرونة بالبصيرة النافذة التي تخرر الهندوسي من الصفات السلبية مثل: الكبر والعجب، والجهالة والتغلب، على عشرة من الشرور التي تلازم الإنسان وهي: أوهام النفس والشك وبذل الجهاد من أجل القوت والملذات والشهوات الجسدية والرغبة في إدامة الحياة السماوية والعجب والكبر وادعاء التقوى والاستقامة والجهل وحب الحياة الأرضية والحقد وكراهية الآخرين. 32 وهو ما اصطلح عليه صوفية الإسلام بالفناء الأخلاقي أي فناء الأخلاق المذمومة ببقاء الأخلاق الفاضلة والممودة، ومن هنا جاء تعريف بعضهم للتصوف بأنه "تخلية وحلية"، أو كما عرفه أبو محمد الجريري (ت 331 هـ) حيث قال: "هو الدخول في كل خُلُق سَني، والخروج من كل خلق دني."

وفي هذا النمط من اللاوعي، الصوفي المفارق، يتحقق الصوفي بنوع معرفة، ليست كَسْبِيَّة تنال بحيلة الدليل وإعمال الفكر بل هي معرفة تنفث في روع المتصوف، إنها معرفة -هي زعمهم- منح وعطايا يغرفها الصوفي الواصل من بحر العطاء الرباني اللامتناهي (وهي المعرفة اللدنية والحكمة الخالدة) تبدأ في صورة لوامح ولوامع وبوراق عابرة ولحظية ثم تستقر وتتمكن في صيغة معرفة حقة تتسم بأهما يقينية وتتسم باللحظية والمباشرة، من غير حجاب وواسطة من حد أو عقل وبالصدق الضروري. 33 ومع اتساع دائرة الدراسات النفسية والاجتماعية فقد أضيف -اعتباطاً- نمطان آخران من الوعي الصوفي إلى النوعين السابقين، وهكذا نلتقي في الدراسات المعاصرة بالأنماط الأربعة التالية، مما يعتبر في نظر الباحثين في التجربة الصوفية وعياً صوفياً:

1. التصوف المفارق: فوق الطبيعي وهو ما أسميناه بالنمط المنكفيء على الذات، وهو المراد أصالة.

$$
33 \text { ف } 32 \text { انظر : أحمد شبلي، } 1986 \text { عرفان عبد الحميد. دراسات في الفكر العربي الإسلامي، عمان: دار عمار، 1991، ص } 291 \text { وما بعدها. }
$$


2. التصوف الطبيعي: وهو النوع الذي اصطلحنا عليه بالنمط المنفتح على الطبيعة، وإن الله تعالى منبث في العالم الطبيعي، فالله هو الطبيعة والطبيعة هي الله.

3. نمط الوعي الصوفي المتمثل في حالات فقدان الوعي المستثار بالعقاقير والمخدرات وتناول حبوب الهلوسة، وهذا النمط مما يصطلح عليه علماء النفس والاجتماع بالحالات الصوفية المستثارة بالمواد الكيماوية.

$$
\text { 4. الوعي الصوفي الناتج عن الإصابة بأمراض عصابية.34 }
$$

ورغم اعتراض العديد من المهتمين بدراسة التجربة الصوفية في الأديان على اعتبار النمطين الأخيرين حالات صوفية ووصموهما بالتصوف الممسوخ والكاذب ومبررين ردهم بأن الأول مصدره كيماوي وأن الثاني يمثل حالات من الشذوذ النفسي ومظاهر لأمراض عصابية، فإن المهتمين بالدراسات النفسية والاجتماعية يرون أن الباحث في مثل تلك الحالات النفسية والعصابية ليس من شأنه الاهتمام بالأسباب أو العوامل المنشئة لها، وإنما ينحصر همه وقصده في دراسة المظاهر الخارجية البادية على الأفراد، مع توكيدهم بأن تناول العقاقير المخدرة إن تحول إلى الإدمان المزمن، فإنه لا يعين أبداً على تطور وسمو جواني وأخلاقي، بل العكس تماماً، يسوق إلى تحطيم الشخصية الإنسانية وعوقها نفسياً واجتماعياً وأخلاقياً، وأما حالات الهستيريا، والكبت المزمن والاغيار العصبي، وسواها من الأمراض النفسية الأخرى، فهي حالات استثنائية وغير سوية في نظر المنكرين لاعتبارها حالات من الوعي الصوفي، فلا يجوز ولا يصح - في نظرهم- إدراجها ضمن أنماط الوعي الصوفي، ومن هنا اصطلحوا عليها بالتصوف المنتحل والفاسد الذي لا اعتبار له.

على أننا رغم حملات الإنكار تلك، سنلتقي في دراستنا بأنماط من الوعي الصوفي، حتى في دائرة الفكر الصوفي في الإسلام، مشخصة في طوائف من الغلاة الذين أسماهم الصوفية الملتزمين بأدبي الشرع والعقل بالمستصوفة، 35 مثل القلندرية والقزلباشية والعلي إلهية والبكتاشية والنوربخشية والنعمة الإلهية والتختجية.

$$
34
$$

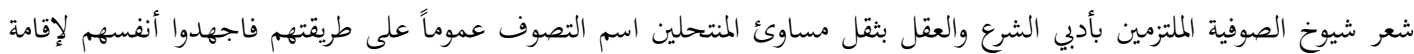

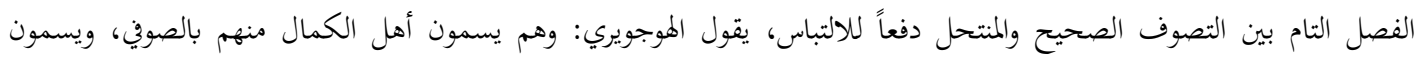


ممن أباحوا شرب الخمر في حلقات السماع وسموها مدامة حيدر، وعرف عنهم تناول المخدرات كالحشيشة قبل إقامة ججالس العربد -طقسية- كذلك نقرأ عن بعض المظاهر النفسية والعصابية المصاحبة للجذبة الصوفية مثل: الجنون المؤقت وحالات الإغماء والاستغراق في أحلام اليقظة-الفنطاسيات، وادعاء الخوارق والشعبذة.

\section{الخصائص العامة المشتركة للتجربة الصوفية:}

انتهى عالم النفس الأمريكي المعروف وليم جيمس في دراسته الموسومة ب"تنوعات الخبرة الدينية" وفي الفصل الذي خصصه للحديث عن التجربة الصوفية الذي استغرق الصفحات (417-330) وأيده فيما ذكر من خصائص مشتركة تعم التجربة الصوفية، على اختلاف دائرةا الدينية والحضارية آخرون من مؤرخة التصوف المقارن إلى أن أهم الخصائص المشتركة للخبرة الصوفية أربعة هي:

1. الاستعصاء على التعبير: بمعنى أن محتوى الخبرة الصوفية ومضموها - كما أسلفنا في المقدمةومن حيث أها بتربة ذاتية وفردانية خالصة، وتمثل حالة من الوعي المفارق مما لا يمكن التعبير عنها أو وصفها بالكلام والخطاب، ولذذا أيضاً لا يمكن نقلها إلى الآخرين وهذه الخاصية قدر مشترك في التجربة الصوفية على تنوع دائرةا الدينية، وهي الخاصية التي أسماها الإمام بكلل اللسان وابن عربي بالخرس واصطلح عليها صوفية الهندوسية بالصمت المطلق.

إن الصمت ظاهرة مستحكمة في التجربة الصوفية لأن الذي يعانيها، يبدأ المحاولة عادة بغلق منافذ الحواس كلياً (في الهندوسية) وذلك استباقاً وتمهيداً لانفتاح البصيرة الجوانية واستقبالاً للمعرفة النورانية التي سرعان ما تنبثق من أعماق أغوار النفس التي وصلت في معراجها الروحي إلى الحق تعالى (عند صوفية الإسلام) أو اتحدت بالنفس الكلية في التصوف الهندوسي.

المتعلقين بهم وطلابهم بالمتصوف...والمتصوف هو من تشبه بهم من أجل المال والجاه وحظ الدنيا...المتصوف عند الصوفية كالذباب،

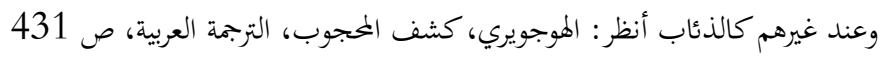

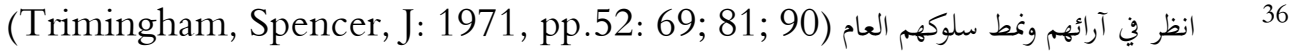

37 Arberry, A.J. Revelation and Reason in Islam, New York: Macmillan Co.,1956, p. 110 
وقد أشار المستشرق المعروف نيكلسون في دراساته المستفيضة عن التصوف الإسلامي وتاريخه وشخصياته ونظرياته إلى هذا الأمر فقال: "إن صوفية الإسلام شأفم في ذلك شأن الصوفية جميعاً، يدركون أن الغاية التي يريدون تحصيلها من الطريق الصوفي ليست مما يقع في نطاق العلم أو الوصف بالألفاظ، فليس لغير من يتذوق أحوال الصوفية أن يفهم هذه الأحوال، وليس لهم أنفسهم إلا أن يتذوقوها، أما الوصف بالألفاظ فيقصر دون التعبير عن هدف الصوفي، وإن كان لا يقصر عن وصف طريق السلوك إلى هذا الهدف، من أوله إلى آخره."38 ويؤيد وليم جيمس هذه المعاني قائلاً: "إن التجربة الصوفية تتحدى التعبير، فليس في الإمكان التعبير عن مضموها في كلمات، ومن ثم فإن كيفيتها لا بد لمعرفتها من تذوقها مباشرة." وهذا عين ما صرح به الصوفية الذي قال الإمام الغزالي في وصف بتربتهم الجوانية: "من ذاق عرف" وعبر عنها في الإحياء (25/3) بقوله: "النصوف أمر باطن لا يُطلع عليه."

2. النسقية الفكرية: من المفترض والأمر الطبيعي أن تتعارض معطيات الخبرة الصوفية وبحافي معنى النسقية الفكرية من حيث إنما وعلى تنوع أنماطها وصورها، مواجيد وجدانية-عاطفية، ولا تقع في نطاق العلم، فهي ليست علماً، لأن العلم منهجه الاستدلال والخبرة الحسية ولذا أمكن التحقق من صدق قضاياه بالرجوع إلى الواقع وشهادته.

ومع هذا التناقض الصارخ بين الخبرة الصوفية والمستفاد من العلم، فإن التجربة الصوفية في نظر الخائضين لمعتركها، تمد صاحبها بنوع من النسقية الفكرية، بل هي المعرفة اليقينية حقاً. ولغياب شهادة التصديق على هذه المعرفة النورانية، لم يكن أمام صوفية الأديان إلى التذرع بالشهادة العالمية، على إمكاغا وتحصيلها، فالصوفية على ما بينهم من تباين الأصقاع واختلاف الأزمان والدوائر الحضارية التي ينتمون إليها، فإِغم متفقون على جوهر التجربة.

38 R.A. Nicholson. Studies in Islamic Mysticism, Cambridge: Cambridge University Press, 1961,

39 James, William. The Varieties of Religious Experience, New York: Doubleday \& Co. Inc., 1978 
وقد ساق الإمام الغزالي رداً على منكري المعرفة التي طريقها الخبرة الصوفية فقال في الإنكار عليهم: "فمن ظن أن الكشف موقوف على الأدلة المحرة، فقد ضيق رحمة الله الواسعة فأما النظار وذوو الاعتبار فلم ينكروا وجود هذا وإمكانه وإفضائه إلى هذا المقصد على الندور، فإنه أكثر حالات الأنبياء والأولياء، ولكن استوعروا هذا الطريق واستبطأوا ثمرته واستبعدوا استجماع شروطه، وزعموا أن محو العلائق إلى ذلك الحد كالمتعذر، وإن حصل في حالة فثباته أبعد منه، إذ أدنى وسواس وخاطر يشوب القلب. 40 ويقول أيضاً: "ولو اجتمع العقلاء كلهم من أرباب الذوق على تفهيمه (المنكر له) معنى الذوق لم يقدروا عليه."41 ويشير إلى وجه الاستحالة هذه العلامة ابن خلدون فيقول: "ليس البرهان والدليل بنافع في هذا الطريق، رداً أو قبولاً، إذ هي من قبيل الوحدانيات."42 ويقترب هنري بردسون من مقولة الغزالي في الإنكار على منكري المعرفة الصوفية، بل يكاد يعبر عما قاله الغزالي حرفياً. 43

3. اللحظية والتلقائية: ويراد بها الغياب اللحظي المؤقت للوعي والإدراك؛ بالذات وبالاعتبار، في مقام الشهود عند صوفية الإسلام أو الفناء عن السوى -كما عبر عنه الإمام ابن تيمية، وعن كل ما يدرك بالحس، وعن كل ما يخطر في العقل، بل عن كل فعل وشعور، وذلك بالاستغراق بالكلية في المنطق، أو كما عبر عنه صوفية الإسلام، حصر القلب في الله تعالى وتركيز التأمل في صفاته. ومع هذه الحالة بالغياب غياب الوعي والشعور - فإن الصوفي يرقى إلى نوع وعي مفارق وغير طبيعي أو اعتيادي يصطلحون عليه بالشعور المفارق المجاوز تنتفي فيه، ومعه، كل معاني الثنائية والكثرة، ويكون حال الصوفي كحال "الطائر

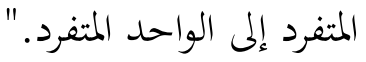

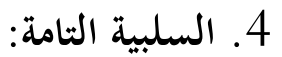

$$
\begin{aligned}
& 40
\end{aligned}
$$

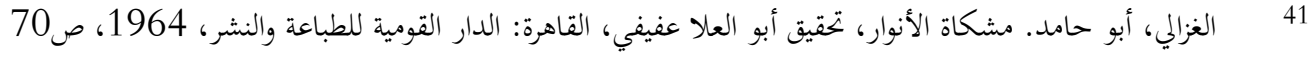

$$
\begin{aligned}
& 42
\end{aligned}
$$

هنري برجسون. منبعا الدين والأخلاق، الترجمة العربية لسامي الدوربي، ومراجعة عبد الله عبد الدائم، القاهرة: الميئة المصرية للتأليف

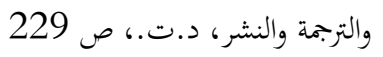


ويقصد بها أن السالك للطريق الصويف من حيث أنه معراج روحي صاعد، ورغم ما ييذله من جهد ومعاناة أثناء سيره المحفوف بالعقبات، للارتقاء من مقام إلى الذي يعلوه طلباً للتحقق بالمعرفة اليقينية الحقة، فإن تلك المعرفة ليست ثمرة جهاه ومعاناته، بل هي معرفة متلقاة، في صورة وهب إلهي ومنحة ربانية، وليس للصوفي إلا أن يتحضر ذاته ويتهيأ لاستقبال الأنوار الإلهية في صورة إلهام وكشف لدني، والانتقال من عالم الظلمات والجهل والرغبات والشهوات والإرادات إلى عالم النور الساطع والمعرفة الحقة التي لا تحتاج على دليل من خارجها. وعن هذا الفهم لمسعاهم فقد ميز الصوفية في الأديان عامة بين العلم والمعرفة، أو بين علم البرهان والاستدلال والكشف الشهودي العياني، أو بين علم نظري قوامه البحث والاستدلال، ومعرفة كشفية حضورية وصادقة بالضرورة، لخصها بطريق المعارضة والمقابلة بين العلم والمعرفة الشيخ ابن عربي قائلاً: "علوم الفكر بكل وجه ما تقوم مقام علوم الذكر والوحي والوهب الإلهي، في الرفعة والمكانة ...لأن الأفكار محل الغلط."44 وأكد هذا التقابل بين العلم والمعرفة من بعده شيوخ الصوفية عامة، فقال أبو المواهب الشعراني (ت 973ه): "فلا علم إلا ما كان عن كشف وشهود، لا عن نظر وفكر وتخمين" (رسالة ابن عربي إلى الفخر الرازي، 5/1)، ويزيد هذه التفرقة بين العلم والمعرفة بياناً ابن عباد الرندي فيقول: "وإن شئت قلت هما ولايتان، ولاية دليل وبرهان، وولاية شهود وعيان، فولاية الدليل والبرهان لأهل الاعتبار، وولاية الشهود

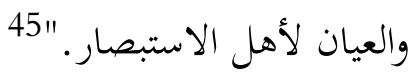

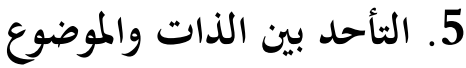

استدرك وليم جيمس على ما ذكره في كتابه آنف الذكر تنوعات الخبرة الدينية، فأشار إلى هذه الخاصية في مؤلفه الآخر الفلسفة البراغماتية pragmatism.

والحق فإن هذه الخاصية من أخص أوصاف التجربة الصوفية وفي مختلف التصوفات، بل إن التصوف في جوهره ودلالته الأولى والدقيقة لا يعني إلا الاتحاد مع الخالق تعالى عند صوفية الأديان السماوية أو مع

$$
44
$$

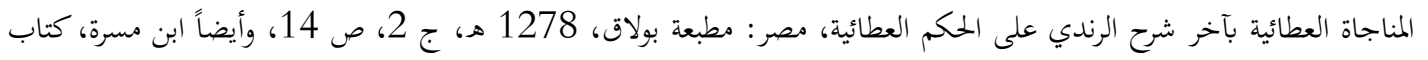

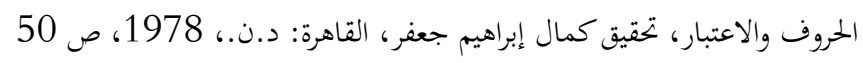


النفس الكلية-الكونية في غيرها، "فالتصوف وفي دلالته التاريخية الدقيقة لا يخرج عن كونه سلوك طريق

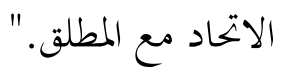

وعن هذا عرف التصوف عموماً بأنه: "طيران المتفرد بذاته إلى الواحد حتى عرف أفلوطين الجذبة الصوفية بأهما فن الاتحاد مع الواحد الذي اصطلح عليه القباليون اليهود ب devukut الذي يفيد معنى "الاتحاد بالله"، عن طريق محو النوازع الدقيقة والاستغراق بالكلية في الذات الإلهية.

وحذراً من الوقوع في الحلول والاتحاد ووحدة الوجود والإدانة بالكفر والمروق عن الدين فإن الصوفية الملتزمين بأحكام الشريعة في الأديان السماوية، حاولوا جهد المستطاع التفرقة بين الفناء الإرادي (الفناء عن إرادة السِّوى) والفناء الشهودي (الفناء عن شهود السِّوى) ثم الفناء الوجودي أو القول بوحدة الوجود، فصححوا الأول والثاني واعتذروا للقائلين بكما في حين حكموا -كما فعل الفقهاء والمتكلمون في الأديان السماوية عامة- بالكفر على القائلين بالوحدة الوجودية.

واستدراكاً على مجمل هذه الخصائص التي أشار إليه وليم جيمس وآخرون من دارسي الوعي الصوفي فإن المؤرخ للحركات الصوفية يلحظ عدداً من المظاهر الثانوية والهامة التي لازمت تلك الحركات، فثمة مظاهر اجتماعية وأخلاقية وسلوكية عامة ومتماثلة اقترنت بالحركة الصوفية عبر التاريخ. من هذه المظاهر أن التجربة الصوفية تسبقها في الغالب من الأحيان وتمهد لها حالة نفسية تتمظهر في الشعور بغياب الطمأنينة وعدم الراحة والقلق النفسي والاضطراب الفكري اصطلح عليه صوفية الأديان بالليالي المظلمة ويعتبرون هذه الحالات بوابة التوبة وداعية الإنابة والشروع في خوض التجربة الصوفية ومعاناة الطريق الصوفي آملين تجاوز تلك الحالات والوصول إلى الطمأنينة الجوانية، والراحة النفسية والتغلب على حالات الشك باستعادة اليقين، هكذا كان الحال مع أكابر رجال الحركة الصوفية في الأديان من أمثال القديس أغسطين الذي بحرع من 
مرارات موجات التنقل بين المذاهب والأديان والاستغراق التام في شهوات الجسلد، والسقوط في مهاوي الشك والإلحاد كما حكاها في كتابه الاعترافات. 47

وقد صور الإمام الغزالي هذه الحالة التي تسبق اليقظة الصوفية في كتابه الذي حكى فيه تردده بين المذاهب وشكوكه الفكرية وأزماته النفسية فقال: "فلم أزل أتردد بين تجاذب شهوات الدنيا ودواعي الآخرة قريباً من ستة أشهر أولها رجب سنة ثمان وثمانين وأربعمائة، وفي هذا الشهر جاوز الأمر حد الاختيار إلى الاضطرار إذ أقفل الله على لساني حتى اعتقل عن التدريس، فكنت أجاهد نفسي أدرس يوماً واحداً تطييباً لقلوب المختلفة إليّ فكان لا ينطق لساني بكلمة واحدة استطيعها البتة حتى أورثت هذه العقلة في اللسان حزناً في القلب، بطلت معه قوة الهضم ومراءة الطعام والشراب، ثم لما أحسست بعجزي وسقط بالكلية اختياري، التجأت إلى الله تعالى، التجاء المضطر الذي لا حيلة له، فأجابني الذي يجيب المضطر إذا

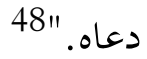

ومن هذه المظاهر أيضاً أنه ظهرت وتظهر في جنبات الحركات الصوفية عامة نزعات هدامة تبشر بالفوضى الأخلاقية والاتحاهات العدمية ودعوات إسقاط الفضائل الأخلاقية المتوارثة من الاعتبار مما تسبب في قيام صراع تاريخي دام واتصل بين أدعياء التصوف من زنادقة المستصوفة وبين الفقهاء، باعتبارهم حماة الشريعة، والمتكلمين باعتبارهم حراس العقيدة الصحيحة. وهكذا ظهرت طوائف وفرق وجماعات تدعي التصوف صرحت بالكفر والإلحاد واستباحة الحرمات واسقاط التكاليف والقول بالحلول والاتحاد ووحدة الوجود والنظر إلى الشواهد، مما دفع الفقهاء والمتكلمين في الأديان السماوية الثلاث إلى إصدار فتاوى ضد مدعي التصوف المنحرف، وتكفيرهم. حصل هذا -كما مر بنا- في اليهودية وفي المسيحية وفي الإسلام أيضاً. يقول الإمام الذهبي في فلسفة الفناء الصوفية: "الفناء والبقاء من ترهات الصوفية، دخل من بابه كل إلحادي وزنديق، وأراد قدماء الصوفية بالفناء نسيان المخلوقات وفناء النفس عن التشاغل بما سوى الله، ولا يسلم إليهم هذا أيضاً، بل أمرنا الله ورسوله بالتشاغل بالمخلوقات، ورؤيتها والإقبال عليها وتعظيم خالقها."

47 Saint Augustine. Confessions, translated by Henry Chadwick, New York: Oxford University Press, 1991

$$
\text { الغزالي، أبو حامد. المنقذ من الضال، القاهرة: دار الكتب الحديثة، 1957، ص } 106
$$


(جامع الأصول، 766/4) ويقول ابن تيمية: "كثير من هؤلاء يخرجون عن ربقة العبودية مطلقاً، بل يزعمون

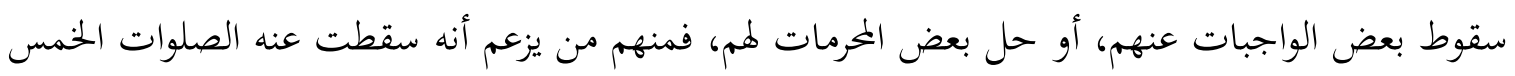
لوصوله إلى المقصود، وربما قد يزعم سقوطها عنه إذا كان في حال مشاهدة وحضور، وقد يزعمون سقوط الجماعات عنهم استغناء عنها، بما فيه من التوجه والحضور ومنهم من يزعم سقوط الحج عنه، مع قدرته عليه لأن الكعبة تطوف به، أو لغير هذا من الحالات الشيطانية ومنهم من يفطر في رمضان لغير عذر شرعي زعماً منه استغناءه عن الصيام، ومنهم من يستحل الخمر زعماً منه أها تحرم على العامة الذين إذا شربوها تخاصموا وتضاربوا دون الخاصة من العقلاء، ويزعمون أها تحرم على العامة الذين ليس لهم أعمال صالحة، فأما أهل النفوس الزكية والأعمال الصالحة فتباح لهم دون العامة. 49

ويصف التهانوي صاحب الحلولية من المستصوفة فيقول: " الحلولية فرقة من الصوفية القائلين بإباحة النظر إلى النساء والمرد يرقصون ويطرقون، ويقولون: إن هذه من صفات الله تعالى التي حلت علينا، وهي مباح، وهذه كفر مخض، وبعضهم يقيمون بجالس لهم، وعليهم لباس الدراويش ويتصايكون بآه وواه، وبالبكاء

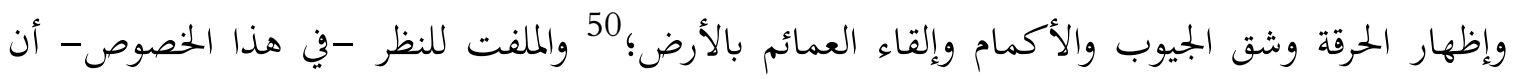
هذه الأوصاف قد تلبست بها جماعة التقاة الحاسديم الذين، كما يشير روبرت إم سلتزر (1980) اعتادوا في مجالس الذكر التي يقيموفا التصفيق والقفز والدوران والهياج العاطفي مما يصطلح عليه في التصوف المقارن ب"العربيد-طقسية" والتي هي أيضاً من أهم وأخص صفات الحركات الطقوسية المنتشرة في الولايات المتحدة حديثاً.

على أن الموضوعية والحيدة العلمية تقتضينا أن نقول أن شيوخ التصوف الملتزم بأحكام الشرائع في الأديان السماوية قد بادروا قبل الخصوم إلى إدانة هذه الشذوذات في العقيدة والانخرافات في السلوك وكفى أن نستشهد بأقوال أئمة الصوفية المعتبرين في الإسلام أمثال الجنيد البغدادي والقشيري وحجة الإسلام الغزالي وآخرين لا يكصون ممن حملوا حملات قاسية على أولئك الذين ادعوا التصوف كذباً ونفاقاً والذي ما قصد به

$$
\begin{aligned}
& 49 \\
& 50
\end{aligned}
$$


شيوخه الكبار إلا تمام الأدب، وكمال الأخلاق والالتزام التام بأحكام الشريعة وحدودها. 51 يقول عبد الوهاب الشعراني (1953): "ومن شأن المريد أن يحافظ على آداب الشريعة والمشي على ظاهرها ما أمكن، فإن الترقي كله في امتثال أمر الشرع. هذا أمر قد أغفله غالب من شم رائحة التوحيد من أهل هذا الزمان، فيصير يتعدى حدود الله في مأكله وملبسه وكلامه وفعله. وهذا كله زندقة لرفضه الشرائع." وهكذا كان الأمر في التصوف اليهودي الذي قرر مبرزوه بأن سلوك طريق التصوف مبتدؤه الالنزام التام بأحكام الشريعة الموسوية (الهالاخاه) فيقول يوسف دان: "أن الكامل من كل الوجوه فقط اعتبر مرشحاً لسلوك الطريق الصوفي ونيل الغاية المرجوة من سلوك الطريق."52

على أننا نبه ثانية إلى أن طبيعة التجربة الصوفية، من حيث أها تجربة وجدانية-عاطفية محضة، مشروع بطبيعته منفتح على الفوضى الخلقية والانخراف في العقيدة والسلوك. 53 هكذا كان الحال عبر تاريخ التصوفات في الأديان جميعاً، حيث نبتت في أحضان الحركات الصوفية النزعات العدمية الآثمة والاستهانة بالأحكام الشرعية والتحلل منها وادعاء الدجل والشعبدة والمخارق لتصبح التجربة الوجدانية ساحة مشاعة لنمو الأساطير والخرافات والكهانة الكاذبة والرؤيات المختلفة وتعاطي السحر والاعتقاد بالقوة السحرية للحروف والأرقام (الجماعات الحروفية في التصوف الشيعي والتصوف اليهودي).

وتقترن بهذه الدعاوى المرجفة أنماط سلوكية منحرفة مثل إقامة حفلات العربيد-طقسية التي يتخللها الرقص والغناء والتصفيق والقفز والدوران حول النفس والهياج العاطفي والقول بالشواهد، 54 والتعبير عن الحب الإلهي في عبارات جنسية مفضوحة بل وإقامة حفلات للعهر الجماعي المقدس -عند الزنادقة والحلوليينبرغم كاذب مفاده أن المتصوف الذي تحقق بالتأله التام، يكون معصوماً عن اقتراف الذنوب، ومن ثم فكل

فتاح، عرفان عبد الحميد. نشأة الفلسفة الصوفية وتطورها، مرجع سابق، ص 73 وما بعدها ... . . 51 52 Dan, Joseph. Jewish Mysticism and Jewish Ethics. ...

53 ibid

القول بالشواهد الذي فرنه القشير بالشرك والكفر ووصفه الشيخ عمر السهروردي بالزندة والإلحاد ويقول عن هذه الطائفة من المترسمين 54

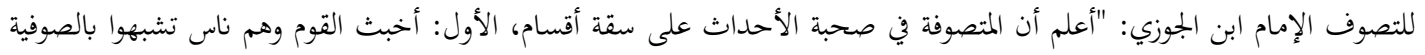

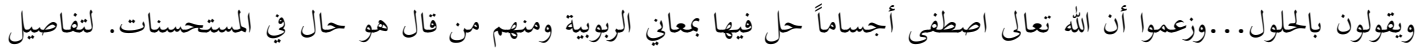

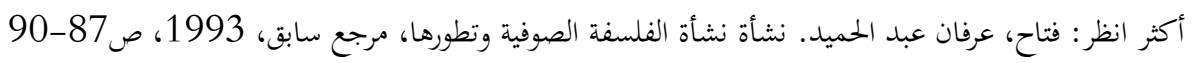


سيئة يقترفها، صغيرة كانت أم كبيرة، لا تعتبر اجتراحاً للسيئات، لأنه بتألهه قد تشبه بالله، المنزه عن

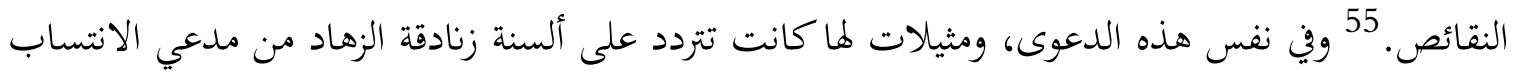

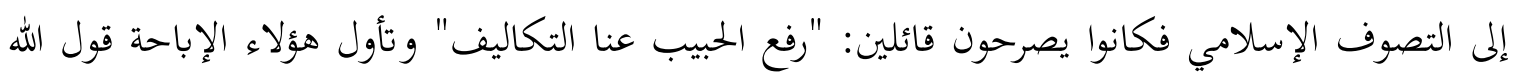

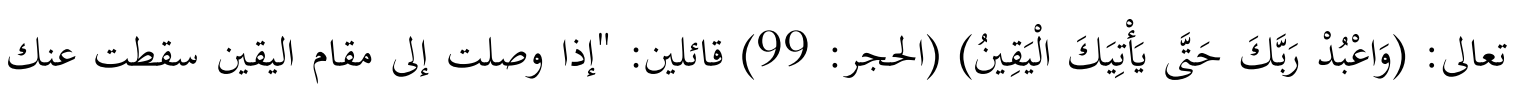

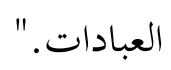

ومن المظاهر التي اقترنت باستمرار بالحركة الصوفية في مختلف أنماطها وتنوع الدائرة الدينية والثقافية التي

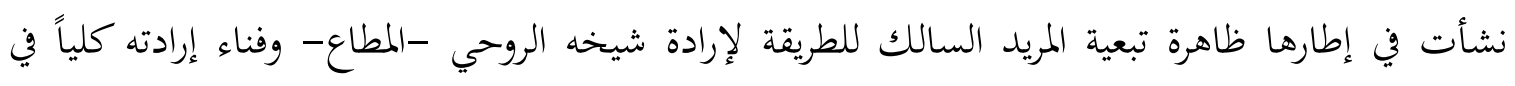

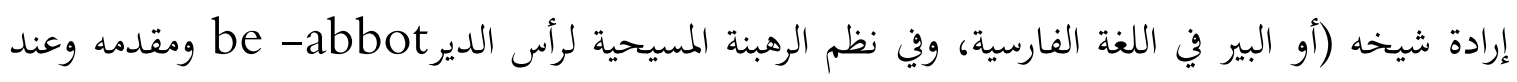

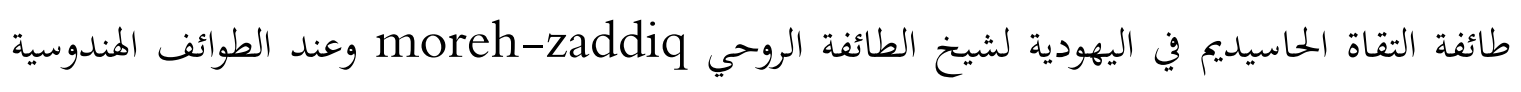
guru

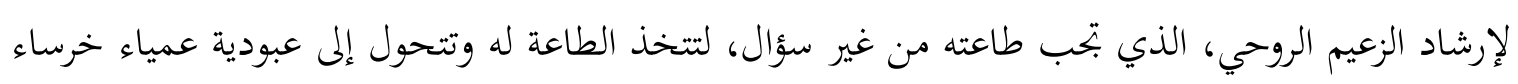

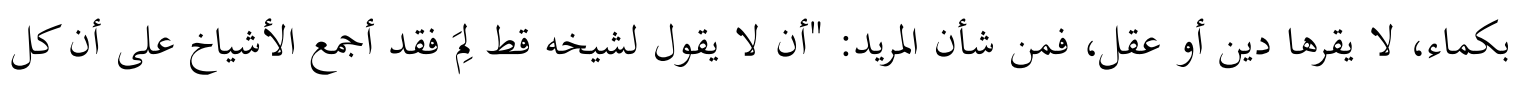

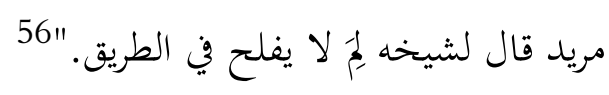

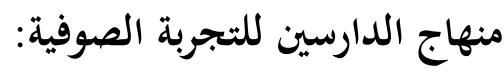

هل التجربة الصوفية بخصائصها العامة المشتركة التي فصلنا في صورها بحربة واحدة ومتمائلة في الأديان

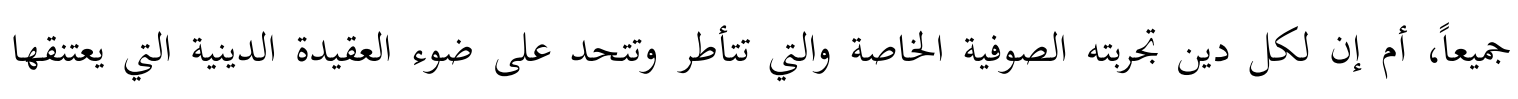

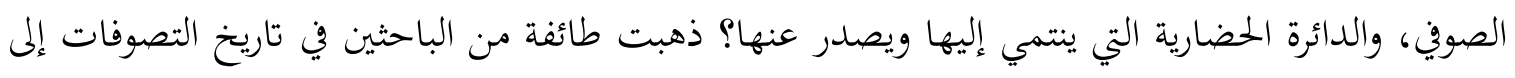

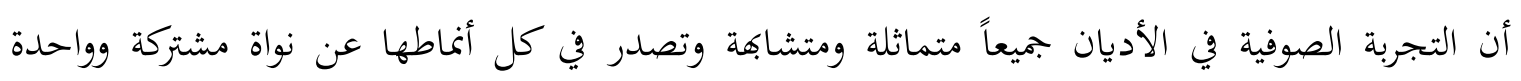

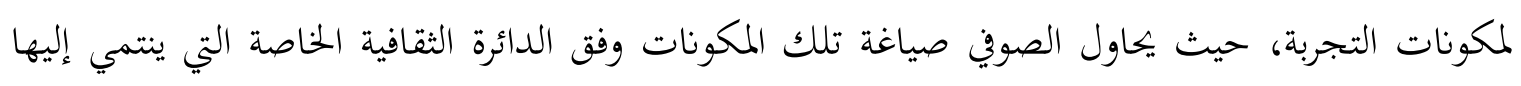

55 Elidada, Mircea. Encyclopedia of Religion, ... Vol. 2, p

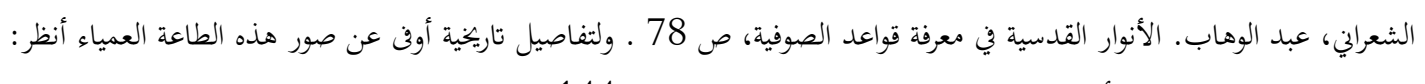


بغية التوافق مع معالم تلك الثقافة، وبعبارة صوفية: "الإسلام ربط الحقيقة بالشريعة"، وجاء إسباغ الشريعة من

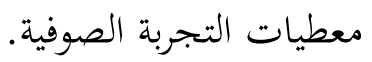

وذهبت طائفة ثانية من مؤرخي التصوف المقارن إلى نقيض ذلك، فأكدت وقررت بأن لكل دين تصوفه الخاص به الصادر عن تعاليمه ومحدداته. يقول زيهنر: "إن التجربة الصوفية في الغالب تكون مشدودة وموصولة بدين بعينه، تصدر عن تعاليمه، وتتشكل على ضوئها."57 وعن هذا الفهم كان تصنيفه للتجارب الصوفية تبعاً لتوافقها مع تعاليم المسيحية أو تعارضها معها. وأيده فيما ذهب إليه جيرشوم شخوليم المتخصص في دراسة التصوف اليهودي والأستاذ بالجامعة العبرية حيث أكد القول بأنه ليس ثمة تصوف عام من غير هوية معينة، بل هناك تصوف خاص ومتمايز في كل دين فالصوفية يصدرون عادة عن تعاليم عقيدةم الدينية.

والذي نميل إليه ونرجحه: أن النظرية الأولى تسوق في أغلب الأحايين إلى المصادرة التاريخية والتعميمات الجارفة بالتماس أوجه التشابه والمماثلة بين الدوائر الصوفية ورد اللاحق إلى السابق من غير قرائن تاريخية تؤيد ذلك، وهي النظرة التي هيمنت على دراسات المستشرقين عموماً، ممن أرجعوا الحركة الصوفية في الإسلام، بكل ما تنطوي عليها من مراحل وتطورات إلى التأثيرات الأجنبية وصاروا يلتمسون لكل مفردة في التصوف الإسلامي مرجعية أجنبية، على خلاف بينهم في تحديد تلك المرجعية أهي الرهبنة المسيحية، أم التصوف البوذي والهندوسي، أم الفلاسفة اليونان، متغافلين كلياً عن فعل وأثر العوامل الذاتية النابعة من تفسيرات الصوفية لتعاليم الإسلام وحركة المجتمع الإسلامي الذاتية.

أما النظرية الثانية فبدورها تتنكر كلية للمعالم والخصائض المشتركة التي أحصيناها والتي في مجموعها تشكل -لا ريب- قاسماً مشتركاً وتماثلاً قوياً، وإلا كيف تبرر تلك الخصائض المشتركة العامة، إلا أن نقول بأها من لوازم الوعي الصوفي الموروثة عموماً.

57 Zaehner, R.C. Mysticism: Sacred and Profane, 1957, p

58 Scholem, Gershom. Major Trends in Jewish Mysticism, New York: Schoken Books, 1941 
ومن هنا لزم دراسة الظاهرة الصوفية بالمنهجين معاً، باعتبارهما متكاملين؛ دوما تضاد بينهما؛ فينصرف الباحث عندئذ إلى رصد العوامل المعقدة المتضافرة -الذاتية- لنشأة الظاهرة في كل دين، ثم يحاول التماس وجوه الشبه والمماثلة بين التجارب الصوفية في الأديان، من غير وقوع تحت التأثيرات الظاهرية للمنهج الشكلي الذي همه الأول التماس الأشباه والنظائر، ورد اللاحق إلى السابق بوحي سابق من نظرية التأثير الأجنبي الذي يُغفل ، ويسقط من الاعتبار، فعل العوامل الذاتية في نشأة الظاهرة وتطور مبانيها 